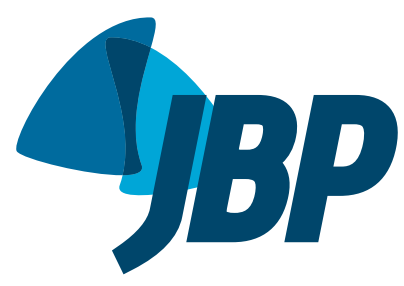

1. Pediatric Residency Program, Pontifícia Universidade Católica do Rio Grande do Sul, Porto Alegre (RS) Brazil.

2. Post-Graduate Degree in Pediatrics and Children's Health, Pontifícia Universidade Católica do Rio Grande do Sul, Porto Alegre (RS) Brazil.

3. Medical School, Pontifícia Universidade Católica do Rio Grande do Sul, Porto Alegre (RS) Brazil.

4. Post-Graduate Degree in Cell and Molecular Biology, Universidade Federal do Rio Grande do Sul, Porto Alegre (RS) Brazil.

5. Centro Infantil, Instituto de Pesquisas Biomédicas, Pontifícia Universidade Católica do Rio Grande do Sul, Porto Alegre (RS) Brazil.

a. (iD) http://orcid.org/0000-0001-7120-3022

b. (D) http://orcid.org/0000-0003-2350-9443

c. (D) http://orcid.org/0000-0001-5138-3046

d. (D) http://orcid.org/0000-0003-4421-8995

e. (D) http://orcid.org/0000-0002-3264-0374

f. (D) http://orcid.org/0000-0003-0217-3792

g. (D) http://orcid.org/0000-0002-3574-6318

h. (D) http://orcid.org/0000-0002-3906-5456

Submitted: 20 November 2017

Accepted: 12 August 2017

Study carried out at Pontifícia

Universidade Católica do Rio Grande

do Sul, Porto Alegre (RS) Brazil.

\section{Genetic and phenotypic traits of children and adolescents with cystic fibrosis in Southern Brazil}

Katiana Murieli da Rosa',a, Eliandra da Silveira de Limaª, Camila Correia Machado ${ }^{3, c}$, Thaiane Rispoli ${ }^{4, d}$, Victória d'Azevedo Silveira ${ }^{3, e}$, Renata Ongaratto 2, , Talitha Comaru ${ }^{2, s}$, Leonardo Araújo Pinto ${ }^{5, h}$

\section{ABSTRACT}

Objectives: To characterize the main identified mutations on cystic fibrosis transmembrane conductance regulator (CFTR) in a group of children and adolescents at a cystic fibrosis center and its association with the clinical and laboratorial characteristics. Method: Descriptive cross-sectional study including patients with cystic fibrosis who had two alleles identified with CFTR mutation. Clinical, anthropometrical, laboratorial and pulmonary function (spirometry) data were collected from patients' records in charts and described with the results of the sample genotyping. Results: 42 patients with cystic fibrosis were included in the study. The most frequent mutation was F508del, covering 60 alleles (71.4\%). The second most common mutation was G542X (six alleles, 7.1\%), followed by N1303K and R1162X mutations (both with four alleles each). Three patients (7.14\%) presented type III and IV mutations, and 22 patients $(52.38 \%)$ presented homozygous mutation for F508del. Thirty three patients (78.6\%) suffered of pancreatic insufficiency, $26.2 \%$ presented meconium ileus, and $16.7 \%$, nutritional deficit. Of the patients in the study, 59.52\% would be potential candidates for the use of CFTR-modulating drugs. Conclusions: The mutations of CFTR identified more frequently were F508del and G542X. These are type II and I mutations, respectively. Along with type III, they present a more severe cystic fibrosis phenotype. More than half of the sample (52.38\%) presented homozygous mutation for F508del, that is, patients who could be treated with Lumacaftor/Ivacaftor. Approximately $7 \%$ of the patients (7.14\%) presented type III and IV mutations, therefore becoming candidates for the treatment with Ivacaftor.

Keywords: Cystic fibrosis; Mutations; Genetics; Phenotype; Child.

\section{INTRODUCTION}

Cystic fibrosis (CF) is a genetic autosomal recessive disorder, more common in Euro-descendant populations, caused by variations in the gene sequence which codifies the cystic fibrosis transmembrane conductance regulator (CFTR) protein. ${ }^{(1)}$ This gene is located in the long arm of chromosome 7 (locus 7q31), and is divided in 27 exons, generating a protein composed of 1,480 amino acids.

The estimated prevalence in several countries is of 1 for every 2,800-3,500 live births. (2) In Brazil, about 1 out of 10 thousand live births presents with the disorder. ${ }^{(3)}$ Mutations in CFTR establish a multisystemic aspect for the disease, characterized by pulmonary, gastrointestinal and sweat gland disorders. ${ }^{(4)}$

Life expectancy in patients with CF has been improving, and, nowadays, more than half of them have reached adulthood. (2) Such an improvement, among other factors, is owed to the increment in innovative treatments and the advancement of interdisciplinary care addressed to the patient with $\mathrm{CF}^{\left({ }^{(5)}\right)}$ Recently, specific therapies addressed to the CFTR channel, which are able to correct the basic flow, have been developed and approved for use in several countries. These targeted drugs aim at

Corresponding address:

Leonardo Araújo Pinto. Centro Infant, Instituto de Pesquisas Biomédicas, Pontifícia Universidade Católica do Rio Grande do Sul, Avenida Ipiranga, $6.690,2^{\circ}$ andar Jardim Botânico, CEP 90610-000, Porto Alegre, RS, Brazil.

Tel.: 5551 3320-3000. E-mail: leonardo.pinto@pucrs.br

Financing: Coordenação de Aperfeiçoamento de Pessoal de Nível Superior (Capes) and Conselho Nacional de Desenvolvimento Científico e Tecnológico (CNPq). 
transforming CF therapy, making the prescription of drugs more accurate. ${ }^{(6)}$

Some protocols include genetic evaluation to complement neonatal screening and clinical diagnosis of $\mathrm{CF}$, allowing the identification of patients who are eligible to mutation-specific therapies. ${ }^{(7)}$ The variants identified in CFTR are divided in six classes of mutations, based on their functional effects. ${ }^{(1)}$ The relationship between genotype and the clinical consequences of all variants, however, requires further understanding.

This study aimed at reporting the main CFTR mutations identified in a group of children and adolescents followed-up at a multidisciplinary center for CF treatment in the South of Brazil, and at associating such mutations to specific clinical and laboratory characteristics.

\section{METHOD}

This is a cross-sectional, descriptive study. Patients who were followed-up at a reference center in the South of Brazil were included. The subjects with suggestive clinical history who were included had their diagnosis confirmed by laboratory examinations (sweat electrolyte test), and had the identification of two mutations in the CFTR. Figure 1 presents the flow chart of the inclusion of individuals in the study.
The reference center has multidisciplinary staff composed of physicians, nutritionists, physical therapists and psychologists, who regularly follow-up more than 100 patients (children and adults). The patients are periodically followed-up with clinical examinations (assessment of nutritional status and body mass index - BMI), laboratory examinations (albumin, glucose, liver function and stool elastase, according to indication) and spirometry (forced expiratory volume in 1 second - FEV1). Besides, the analysis of sputum culture or oropharyngeal swab is routine, in order to identify the colonization by Pseudomonas aeruginosa (PA). The molecular analysis of CFTR is carried out for all patients with clinical diagnosis (based on the symptoms and chloride in the sweat $>60$ ), but without a definitive genetic diagnosis, in the following order: F508del genotype, kits for the study of mutations and sequencing; the investigation is interrupted when two alleles are identified.

The genotyping of the F508del mutation is the most frequent one in the population with $\mathrm{CF}$, so it was presented in patients with clinical diagnosis. Heterozygotic individuals, or the ones who did not present with this mutation, carried out a panel of mutations with commercial kits of 32 to 97 mutations. In cases in which the genetic change had not been identified in both alleles, the complete sequencing of

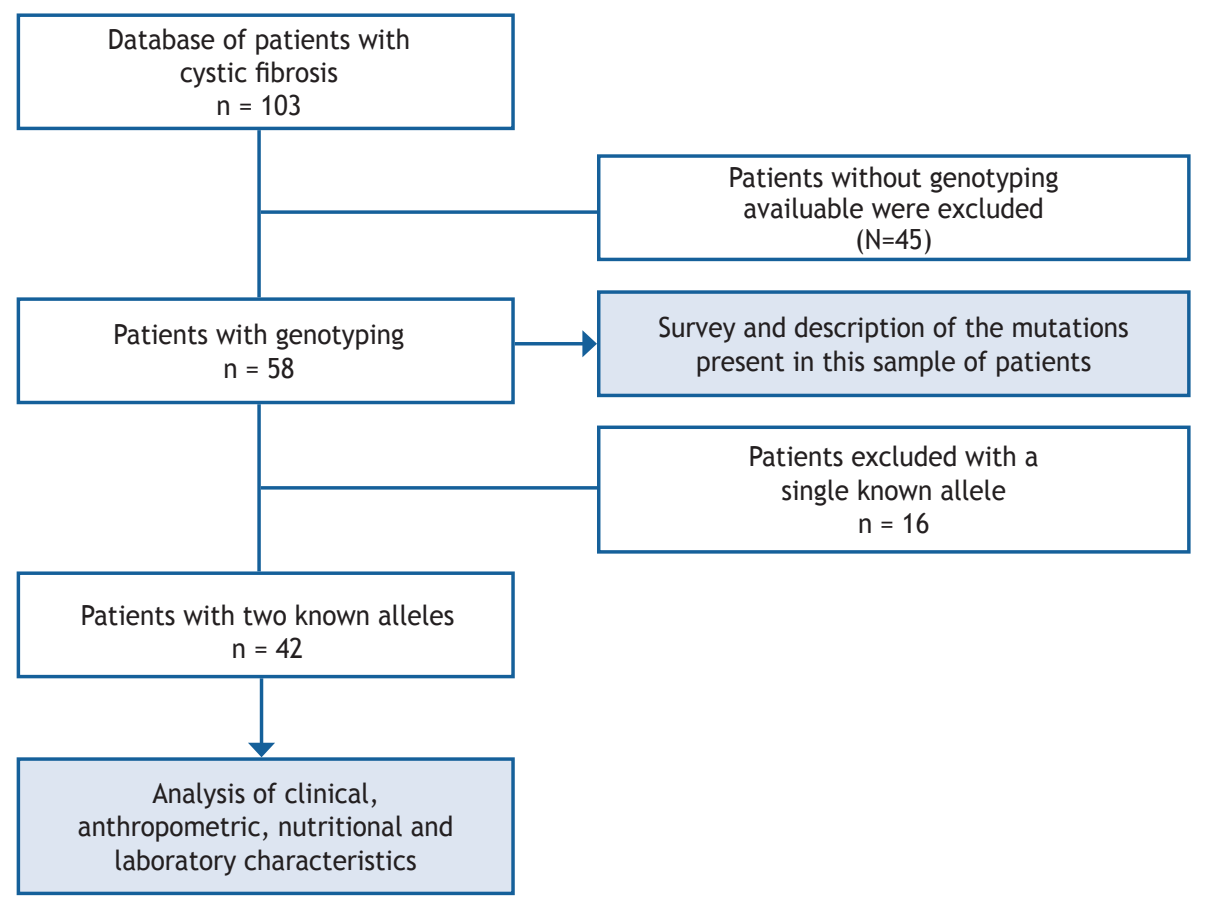

Figure 1. Flowchart of the inclusion of patients in the study. 
the CFTR was performed. The analyses were conducted by different laboratories, according to the availability of the health system or private health insurance plan.

All of the collected data (age, immunoreactive trypsin dosage - IRT, chloride in the sweat, genotype, colonization, spirometry and clinical aspects) were obtained based on the information from the patients' charts. Simultaneously, a literature review was carried out regarding the phenotype described for the most frequent mutations found in our sample.

This study was approved by the Research Ethics Committee of Pontifícia Universidade Católica do Rio Grande do Sul (PUC-RS) and is registered by $n$. 49692115.7.0000.5336.

\section{RESULTS}

Of the 103 patients with CF followed-up at the multidisciplinary center, 58 (56.3\%) have been genotyped. Of these, 42 (72.4\%) were included in the study for presenting both known alleles of CFTR. Table 1 contains data referring to the sweat test and age of the patients, and Table 2 shows the clinical, nutritional, and pulmonary function characteristics according to the identification of the mutations in each one of the alleles. The most frequent mutation was class II, represented by F508del (p.Phe508del), present in 38 patients $(90.48 \%)$, and comprehending $71.43 \%$ (60 alleles) of the total identified alleles. Among the patients who presented with alterations for p.Phe.508del, 57.89\% were homozygous for the mutation. The second most common mutation was class I, with mutation G542X (p.Gly542X), present in six alleles (7.14\%), followed by the mutations N1303K (p.Asn1303Lys) and R1162X (p.Arg1162X), also class $I$, in four alleles $(4.76 \%)$ each.

Of the 42 patients analyzed, 11 (26.2\%) had meconium ileus, in which the following mutations were identified: F508del, G542X and R1162X. All of these represented mutation F508del, and seven patients (63.6\%) were homozygous for this mutation. Three patients (27.3\%) pointed mutation G542X as the second allele, and one patient showed mutation R1162X.

Regarding nutritional status, seven patients (16.7\%) had deficit, characterized by BMI being below the lower limit of normal before or after the condition was diagnosed, and in these cases the following mutations were identified: F508del, R1162X e R347X; all of them contained mutation F508del. Of these, four were homozygous for F508del, two presented R1162X, and one, mutation R347X.

The patients were colonized by different types of bacteria: Staphylococcus aureus (SA), Pseudomonas aeruginosa (PA), Burkholderia cepacia (BC), Haemophilus influenzae and Methicillin-resistant Staphylococcus aureus (MRSA). The most common bacteria was SA, present in 28 of the 42 analyzed patients. PA was observed in 14 patients, all of whom presented the allele F508del; nine (64.3\%) were homozygous for this mutation. BC was present in four patients, who had mutations F508del ( $3 / 8$ alleles), R1162X (2/8 alleles) and N1303K, 711+5G >A, 1078delT.

Table 1. Mutations of the cystic fibrosis transmembrane conductance regulator (CFTR), values of chloride in the sweat test (sweat $\mathrm{Cl}$ ) and current age of patients with cystic fibrosis (CF).

\begin{tabular}{ccccccc} 
Patients (n) & Allele 1 & $\begin{array}{c}\text { Mutation Class } \\
\text { allele 1 }\end{array}$ & Allele 2 & $\begin{array}{c}\text { Mutation Class } \\
\text { allele 2 }\end{array}$ & $\begin{array}{c}\text { Sweat Cl } \\
\text { (mEq/L) }\end{array}$ & $\begin{array}{c}\text { Current Age } \\
\text { (years) }\end{array}$ \\
\hline 22 & F508del & II & F508del & II & $86.51 \pm 26.54$ & $9.01 \pm 7.20$ \\
5 & F508del & II & G542X & I & $84.66 \pm 16.50$ & $11.262 \pm 7.3$ \\
3 & F508del & II & N1303K & II & $67.9 \pm 0.00^{*}$ & $13.56 \pm 3.66$ \\
3 & F508del & II & R1162X & I & $102 \pm 19.09$ & $6.66 \pm 2.57$ \\
1 & F508del & II & D1152H & IV & 28 & 3.4 \\
1 & F508del & II & 3272-26A>G & V & 89 & 11.8 \\
1 & F508del & II & R347H & IV & 88 & 2.11 \\
1 & F508del & II & G85E & II & 76 & 9.7 \\
1 & F508del & II & R1066C & II & - & 20 \\
1 & G542X & I & G551D & III & - & 20.5 \\
1 & P205S & IV & 3132delTG & I & 92 & 13.1 \\
1 & F1303K & II & 1078delT & I & 79 & 7.6 \\
1 & F11+5G & I A & R1162X & I & - & 17.1 \\
\hline
\end{tabular}

Data presented in mean and standard deviation; *only $1 / 3$ of the patients had these data collected. 
Regarding pulmonary function, of the 22 patients who were homozygous for the change in class II p.Phe508del, 12 underwent spirometry, with FEV1 values ranging from 24 to $100 \%$ of the predicted value. The lowest values were observed in patients aged more than 18 years, showing reduction in pulmonary function with age. Of the three heterozygous patients for both mutations F508del/N1303K, one of them underwent spirometry with FEV1 value being $77 \%$, and this patient was also colonized by SA. Of the five patients who were heterozygous for both mutations, three presented FEV1 ranging from 72 and $100 \%$; they were all aged more than 15 years, one colonized by PA, and the other two, by SA. Of the two patients who were heterozygous for both mutations F508del/R1162X, FEV1 corresponded to 46 to 54\%, in percentile, and these patients were aged between 5 and 10 years. In cases in which mutations only appeared once (F508del/3272-26A>G, F508del/G85E, F508del/R1066C, F508del/G551D, P2055/3132delTG, N1303K/1078delT, 711+5G>A/R1162X), FEV1 ranged from 43 to $104 \%$ of the predicted value.

\section{DISCUSSION}

Genotype-phenotype associations in CF, modifier genes, epigenetic factors, and environmental influence help to understand the broad spectrum of disease manifestations, which can range between single to multisystemic involvement, and between mild to severe disease. ${ }^{(8)}$
In this sample of patients with CF, F508deI was the most common mutation, affecting more than $50 \%$ of the homozygous individuals. This class II mutation, responsible for the incorrect processing of the CFTR protein, present in approximately $70 \%$ of the Caucasian population with $\mathrm{CF}^{(9)}$, is considered as a severe mutation, showing the classic phenotype of the disease. Individuals who are homozygous for this mutation usually present with high sweat chloride test results (mean of $98 \mathrm{mEq} / \mathrm{L}$ ), early signs of respiratory symptoms, reduced pulmonary function, pancreatic insufficiency and delayed growth ${ }^{(10)}$. It is the most known and studied mutation that causes CF.

Three other mutations were observed often in our sample: G542X, R1162X and N1303K. Mutation G542X (class I), characterized by a change that results in the absence of the CFTR protein, was the second most prevalent in this sample of patients (six alleles, $7.14 \%$ ), and its frequency is estimated between 2.7 and $8.5 \%$ in Brazil. ${ }^{(11,12)}$ This mutation is responsible for the high incidence of meconium ileus. ${ }^{(13)}$ In our sample, most patients who presented with one allele of the mutation $\mathrm{G} 542 \mathrm{X}$ also had pancreatic insufficiency $(66.7 \%)$. A study that assessed clinical variables in 148 patients with this mutation verified that all of them had pancreatic insufficiency, which shows its severity. ${ }^{(14)}$ Patients with mutation R1162X (class I) presented high sweat chloride test results (mean of $103 \mathrm{mEq} / \mathrm{L}$ ), mild to moderate pulmonary disease and pancreatic insufficiency. Class II mutation N1303K is

Table 2. Genotyping and clinical characteristics of the patients with cystic fibrosis.

\begin{tabular}{cccccccc}
$\mathbf{n}$ & Allele 1 & Allele 2 & MI & PI & $\begin{array}{c}\text { BMI } \\
\text { (percentile) }\end{array}$ & PA & $\begin{array}{c}\text { FEV1 (\% of the } \\
\text { prediction) }\end{array}$ \\
\hline 22 & F508del & F508del & $31.82 \%(7)$ & $77.3 \%(17)$ & $47.27 \pm 33.29$ & $40.9 \%(9)$ & $71.91 \pm 25.48$ \\
5 & F508del & G542X & $60 \%(3)$ & $60 \%(3)$ & $58.2 \pm 27.14$ & $20 \%(1)$ & $89 \pm 19.31$ \\
3 & F508del & N1303K & 0 & $100 \%(3)$ & $53 \pm 39.23$ & $33.33 \%(1)$ & $77 \pm 0.00^{*}$ \\
3 & F508del & R1162X & $33.33 \%(1)$ & $66.66 \%(2)$ & $70.66 \pm 28.99$ & $33.33 \%(1)$ & $50 \pm 5.65$ \\
1 & F508del & D1152H & no & no & 26 & no & - \\
1 & F508del & $3272-26 A>G$ & no & yes & 75 & yes & no \\
1 & F508del & R347H & no & yes & 91 & no & 104 \\
1 & F508del & G85E & no & yes & 99 & yes & 78 \\
1 & F508del & R1066C & no & yes & 92 & no & 82 \\
1 & G542X & G551D & no & yes & 40 & no & 43 \\
1 & P205S & $3132 d e l T G$ & no & yes & 21 & no & 29 \\
1 & N1303K & $1078 d e l T$ & no & yes & 51 & no & 103 \\
\hline
\end{tabular}

MI: meconium ileus; PI: pancreatic insufficiency with laboratory confirmation; BMI: body mass index; PA: colonization by Pseudomonas aeruginosa; FEV1: Forced expiratory volume in 1 second; *only $1 / 3$ of the patients had this data collected $1 / 3$

Data presented in mean and standard deviation or percentage and absolute number. 
among the most common ones(10) for patients with $\mathrm{CF}$, whose frequency is higher than $1 \%$, and shows great variation between countries and ethnicities. (15-17) Considered as a severe mutation, its phenotype is related to severe pancreatic consequences, and may lead to pancreatic insufficiency and diabetes mellitus. ${ }^{(15,16,18)}$ Regarding pulmonary phenotype, the severity of the disease indicates great variability between the different mutations. ${ }^{(15,18)}$ In this sample, patients identified with mutation N1303K in one of the alleles had pancreatic insufficiency.

The other mutations that were found, being each of them presented in one patient, were revised next. Mutation 3132del TG (class I) is rare, and ongoing population studies ${ }^{(10)}$ will help to determine its disease phenotype. Mutation $711+5 \mathrm{G}>\mathrm{A}$ (class I) is more common among Hispanic Americans and in Northeast Italy. A study that included two patients with this mutation associated with F508del showed that these patients had chronic colonization by PA and SA, liver disease and pancreatitis more often. ${ }^{(19)}$

The class III G551D mutation, which is related to the obstruction of the chloride passage through the CFTR protein channel, is associated with pulmonary disease, pancreatic insufficiency, infection by PA and sweat test with increased values. Of the 2,915 patients analyzed, with mean age of 20 years, with this mutation and another mutation for $\mathrm{CF}$, pulmonary function, expressed by spirometry predicted values (FEV1\%), in children aged less than 10 years, ranged from 73 to $128 \%$, and between 10 and 20 years of age, from 49 to $121 \%$. Ninety percent $(n=2,480)$ of the patients presented with pancreatic insufficiency, and $59 \%$, with colonization by PA. ${ }^{(10)}$

Of the patients with $C F, 0.7 \%$ have at least one copy of the G85E mutation (class II). ${ }^{(20,21)}$ Patients with genotype G85E/F508del are similar to the ones homozygous for F508del, when it comes to mean age of diagnosis, mean values of chloride in the sweat, weight/height ratio, spirometry (FEV1), and colonization by PA. ${ }^{(22)}$

Mutation P205S (class IV, characterized by changes in the conduction of chloride through the CFTR protein channel) is associated with a mild phenotype of the disease, being characterized by pancreatic sufficiency ${ }^{(10,23)}$ and lack of gastrointestinal symptoms in most patients. ${ }^{(23)}$ These present sweat chloride test with mean of $84 \mathrm{mEq} / \mathrm{L}$. About $50 \%$ of the patients present colonization by PA or other pathogens, ${ }^{(10)}$ but, in general, demonstrate good evolution.

Mutation 3272-26A $>\mathrm{G}$ (class $\mathrm{V}$, result of the insufficient amount of the normal CFTR protein present in the cellular surface) is associated with the mild phenotype of the disease. Patients with one 3272-26A > G allele and another one in class I-III have less severe clinical manifestations (late diagnosis, better pulmonary function and lower incidence of PA) when compared to patients with two mutations of class I-III. ${ }^{(24,25)}$

Mutation R347H (class IV) is related with pancreatic insufficiency and infection by PA. Of the 161 patients analyzed, with mean age of 23 years who have this mutation and another one for $\mathrm{CF}$, pulmonary function, expressed by the spirometry predictive value (FEV1\%), in children aged less than 10 years ranged from 95 to $139 \%$; among individuals aged from 10 to 20 years, from 78 to $131 \%$, and for those aged more than 20 years, from 34 to $107 \%$.(10)

Mutation R1066C (class II) represents $5 \%$ of mutations for CF in Portugal, and 1\% in Spain, places where a study assessed 28 patients with this mutation. It is a severe mutation, similar to that observed in patients homozygous for F508del.(26)

The presence of mutation $\mathrm{D} 1152 \mathrm{H}$ (class IV), combined with another mutation that causes $\mathrm{CF}$, does not manifest the disease in all patients. Individuals who have this mutation associated with another one, which is known to cause $\mathrm{CF}_{\text {, must undergo frequent }}$ check-up sessions, even if asymptomatic. ${ }^{(10)}$ Most chloride values in the sweat test is $45 \mathrm{mEq} / \mathrm{L}$, and most patients have sufficient pancreas. Mean age at the time of diagnosis is 33 years. According to clinical studies, when it is concomitant to other mutations, D1152H usually causes pulmonary symptoms; however, these are not severe and associated with prolonged survival rates. (27) Mutation 1078delT (class I) can be phenotypically manifested by pancreatic insufficiency, ${ }^{(10)}$ and individuals who have it may present with cirrhosis and mild pulmonary disease. ${ }^{(10,28,29)}$

Currently, the development of drugs which improve CFTR function have shown promising results in the course of the disease, and may be able to contribute with the increasing life expectancy in patients with CF. Two systemic modulators of CFTR were assessed in clinical trials involving patients with $C F$, and approved by the American agency Food and Drug Administration (FDA).

Ivacaftor (VX-770) is a drug that potentializes the CFTR regulator, increasing the ionic function in the cellular surface, improving the obstruction of airways due to the retention of water and increasing mucus purification. This drug can be used for patients who have one of the 33 mutations of classes III and IV among them, mutations G551D, R347H and $1152 \mathrm{H}$, present in three patients (7.14\%) of this study. ${ }^{(30-33)}$ 
Lumacaftor (VX-809) is a CFTR corrector, which increases the amount of protein located in the surface of the cell; its effect is added to Ivacaftor, whose effect potentializes the chloride channels. ${ }^{(33)} \mathrm{A}$ study published in 2014, which included patients of 24 centers of cystic fibrosis in Australia, Belgium, Germany, New Zealand and the United States, showed that the association of Ivacaftor/Lumacaftor does not have significant effects for patients heterozygous for the class II mutation (p.Phe508del); however, patients who are homozygous for the mutation presented a reduction in the frequency of exacerbations and improvement of FEV1. (34)

Recently, the FDA has approved the drug that combines Tezacaftor (VX-661) and Ivacaftor as therapy for patients with CF aged 12 years or more, who carry two copies of the F508del mutation, or for patients who are heterozygous for this mutation associated with a second mutation, which results in the residual function of CFTR. Tezacaftor helps the CFTR protein to dislocate to the cellular surface, and then Ivacaftor helps the ionic CFTR channel to stay open for longer periods of time. Results of two phase 3 studies showed that the treatment with this medication has significantly improved pulmonary function and other health measures in comparison to placebo, showing a favorable safety profile. In our sample of patients, 27 (64.2\%) of them would potentially benefit from this drug.

In conclusion, the mutations more often identified were F508del and G542X, which have higher severity profiles. In our sample, 22 patients $(52.38 \%)$ would be potential candidates for the use of the compound Lumacaftor-Ivacaftor, which has proven to be effective in subjects aged more than 6 years homozygous for the F508del mutation. Besides, three patients (7.14\%) would be candidates for the use of Ivacaftor, drug that can be used in individuals who present with 33 class III or IV mutations, such as G551D, R347H and $1152 \mathrm{H}$, which were present in these patients.

\section{REFERENCES}

1. Elborn JS. Cystic fibrosis. Lancet. 2016;388(10059):2519-31. https://doi.org/10.1016/S0140-6736(16)00576-6

2. Spoonhower KA, Davis PB. Epidemiology of Cystic Fibrosis. Clin Chest Med. 2016;37(1):1-8. https://doi.org/10.1016/j. ccm.2015.10.002

3. Grupo Brasileiro de Estudos de Fibrose Cística. Portal [Internet] [acessado em abr. 2018]. Available from: http://www.portalgbefc. org.br

4. Egan ME. Genetics of Cystic Fibrosis: Clinical Implications. Clin Chest Med. 2016;37(1):9-16. https://doi.org/10.1016/j. ccm.2015.11.002

5. Ikpa PT, Bijvelds MJ, de Jonge HR. Cystic fibrosis: toward personalized therapies. Int J Biochem Cell Biol. 2014:52:192-200. https://doi.org/10.1016/j.biocel.2014.02.008

6. Mayer-Hamblett N, Boyle M, VanDevanter D. Advancing clinical development pathways for new CFTR modulators in cystic fibrosis. Thorax. 2016;71(5):454-61. https://doi.org/10.1136/ thoraxjnl-2015-208123

7. Sosnay PR, Raraigh KS, Gibson RL. Molecular Genetics of Cystic Fibrosis Transmembrane Conductance Regulator: Genotype and Phenotype. Pediatr Clin North Am. 2016;63(4):585-98. https://doi. org/10.1016/j.pcl.2016.04.002

8. Brennan ML, Schrijver I. Cystic Fibrosis: A Review of Associated Phenotypes, Use of Molecular Diagnostic Approaches, Genetic Characteristics, Progress, and Dilemmas. J Mol Diagn. 2016;18(1):314. https://doi.org/10.1016/j.jmoldx.2015.06.010

9. Cystic Fibrosis Mutation Database. Portal [Internet]. [acessado em abr. 2018]. Available from: http://www.genet.sickkids.on.ca/

10. Clinical and Functional Translation of CFTR2. Portal [Internet]. [acessado em abr. 2018]. Available from: https://www.cftr2.org/

11. Araújo FG, Novaes FC, Santos NPC, Martins VC, Souza SM, Santos SEB, et al. Prevalence of deltaF508, G551D, G542X, and R553X mutations among cystic fibrosis patients in the North of Brazil. Braz J Med Biol Res. 2005;38(1):11-5. https://doi.org//S0100879X2005000100003

12. Coutinho CA, Marson FA, Ribeiro AF, Ribeiro JD, Bertuzzo CS Cystic fibrosis transmembrane conductance regulator mutations at a referral center for cystic fibrosis. J Bras Pneumol. 2013;39(5):55561. https://doi.org/10.1590/S1806-37132013000500005

13. Dupuis A, Keenan K, Ooi CY, Dorfman R, Sontag MK, Naehrlich $L$, et al. Prevalence of meconium ileus marks the severity of mutations of the Cystic Fibrosis Transmembrane Conductance Regulator (CFTR) gene. Genet Med. 2016;18(4):333-40. https://doi. org/10.1038/gim.2015.79

14. Cystic Fibrosis Genotype-Phenotype Consortium. Correlation between genotype and phenotype in patients with cystic fibrosis N Engl J Med. 1993;329(18):1308-13. https://doi.org/10.1056/ NEJM199310283291804

15. Osborne L, Santis G, Schwarz M, Klinger K, Dörk T, Mclntosh I, et al. Incidence and expression of the N1303K mutation of the cystic fibrosis (CFTR) gene. Hum Genet. 1992;89(6):653-8.

16. Gonçalves LCS. Fibrose Cística: Estudo das Variações de Sequência do Gene CFTR na População Pediátrica Portuguesa [dissertação]. Porto: Faculdade de Ciências da Universidade do Porto; 2013.

17. Saraiva-Pereira ML, Fitarelli-Kiehl M, Sanseverino MTV. A Genética na Fibrose Cística. Rev HCPA. 2011;31(2):160-7.

18. Farhat R, Puissesseau G, El-Seedy A, Pasquet MC, Adolphe C Corbani S, et al. N1303K (c.3909C>G) Mutation and Splicing: Implication of Its c. [744-33GATT(6); 869+11C>T] Complex Allele in CFTR Exon 7 Aberrant Splicing. Biomed Res Int. 2015;2015:138103. https://doi.org/10.1155/2015/138103

19. Rendine S, Calafell F, Cappello N, Gagliardini R, Caramia G, Rigillo $\mathrm{N}$, et al. Genetic history of cystic fibrosis mutations in Italy. I. Regional distribution. Ann Hum Genet. 1997;61(Pt 5):411-24. https://doi.org/10.1046/j.1469-1809.1997.6150411.x

20. Castellani C, Cuppens H, Macek M Jr., Cassiman JJ, Kerem E, Durie $\mathrm{P}$, et al. Consensus on the use and interpretation of cystic fibrosis mutation analysis in clinical practice. J Cyst Fibros. 2008;7(3):179-96. https://doi.org/10.1016/j.jcf.2008.03.009

21. Chalkley G, Harris A. A cystic fibrosis patient who is homozygous for the G85E mutation has very mild disease. J Med Genet. $1991 ; 28(12): 875-7$.

22. Vertex Pharmaceuticals Incorporated. A Quick Guide to the G85E Mutation. Vertex Pharmaceuticals Incorporated; 2016

23. Chillón M, Casals T, Nunes V, Giménez J, Pérez Ruiz E, Estivil $X$. Identification of a new missense mutation (P205S) in the first transmembrane domain of the CFTR gene associated with a mild cystic fibrosis phenotype. Hum Mol Genet. 1993;2(10):1741-2.

24. Amaral MD, Pacheco $P$, Beck $S$, Farinha $C M$, Penque $D$, Nogueira $P$, et al. Cystic fibrosis patients with the 3272-26A>G splicing mutation have milder disease than F508del homozygotes: a large European study. J Med Genet. 2001;38(11):777-83. 
25. Kanavakis $E$, Tzetis $M$, Antoniadi $T$, Trager-Synodinos J, Kattamis C, Doudounakis S, et al. Mild cystic fibrosis phenotype in patients with the $3272-26 \mathrm{~A}>\mathrm{G}$ mutation. J Med Genet. 1995;32(5):406-7.

26. Liang MH, Wong LJ, Klein D, Shapiro B, Bowman CM, Hsu E, et al. Cystic fibrosis in a Puerto Rican female homozygous for the R1066C mutation. J Med Genet. 1998;35(1):84-5

27. Burgel PR, Fajac I, Hubert D, Grenet D, Stremler N, Roussey M, et al. Non-classic cystic fibrosis associated with D1152H CFTR mutation. Clin Genet. 2010;77(4):355-64. https://doi.org/10.1111/ j.1399-0004.2009.01294.x

28. Duguépéroux I, De Braekeleer M, Participating Centres to the French National Cystic Fibrosis Registry. Genotype-phenotype relationship for five CFTR mutations frequently identified in western France. J Cyst Fibros. 2004;3(4):259-63. https://doi. org/10.1016/j.jcf.2004.07.004

29. Moullier $P$, Jéhanne $M$, Audrézet MP, Mercier $B$, Verlingue $C$, Quéré I, et al. Association of 1078 del T cystic fibrosis mutation with severe disease. J Med Genet. 1994;31(2):159-61.

30. Patel S, Sinha IP, Dwan K, Echevarria C, Schechter M, Southern KW. Potentiators (specific therapies for class III and IV mutations) for cystic fibrosis. Cochrane Database Syst Rev. 2015;26(3):CD009841. https://doi.org/10.1002/14651858.CD009841.pub2

31. Simon RH, Sisson TH. Cystic fibrosis: Investigational therapies. UpToDate. 2017.

32. Athanazio RA, Silva Filho LVRF, Vergara AAV, Ribeiro AF, Ried CA, Procianoy EFA, et al. Diretrizes brasileiras de diagnóstico e tratamento da fibrose cística. J Bras Pneumol. 2017;43(3):219-45. http://dx.doi.org/10.1590/S1806-37562017000000065

33. Wainwright CE, Elborn S, Ramsey BW, Marigowda G, Huang X, Cipolli M, et al. Lumacaftor-Ivacaftor in Patients with Cystic Fibrosis Homozygous for Phe508del CFTR. N Engl J Med. 2015;373(3):220-31. https://doi.org/10.1056/NEJMoa1409547

34. Boyle MP, Bell SC, Konstan MW, McColley Sa, Rowe SM, Rietschel E, et al. A CFTR corrector (lumacaftor) and a CFTR potentiator (ivacaftor) for treatment of patients with cystic fibrosis who have a phe508del CFTR mutation: a phase 2 randomised controlled trial Lancet Respir Med. 2014;2(7):527-38. https://doi.org/10.1016/ S2213-2600(14)70132-8 